\title{
INFRARED-REFLECTIVE COATING ON FUSED SILICA FOR A SOLAR HIGH-TEMPERATURE RECEIVER
}

\author{
Marc Röger \\ German Aerospace Center (DLR) \\ Institute of Technical Thermodynamics \\ Plataforma Solar de Almería, Apartado 39 \\ E-04200 Tabernas, Spain
}

\author{
Christoph Rickers \\ Fraunhofer Institute for Thin Films and \\ Surface Technology IST \\ Bienroder Weg 54E \\ D-38108 Braunschweig, Germany
}

\author{
Ralf Uhlig \\ German Aerospace Center (DLR) \\ Institute of Technical Thermodynamics \\ Pfaffenwaldring 38-40 \\ D-70569 Stuttgart, Germany
}

\author{
Frank Neumann \\ Fraunhofer Institute for Thin Films \\ and Surface Technology IST \\ Bienroder Weg 54E \\ D-38108 Braunschweig, Germany
}

\author{
Christina Polenzky \\ Fraunhofer Institute for Thin Films \\ and Surface Technology IST \\ Bienroder Weg 54E \\ D-38108 Braunschweig, Germany
}

\begin{abstract}
In concentrating solar power, high-temperature solar receivers can provide heat to highly efficient cycles for electricity or chemical production. Excessive heating of the fused-silica window and the resulting recrystallization are major problems of high-temperature receivers using windows. Excessive window temperatures can be avoided by applying an infrared-reflective solar-transparent coating on the fused-silica window inside. Both glass temperatures and receiver losses can be reduced. An ideal coating reflects part of the thermal spectrum $(\lambda>2.5 \mu \mathrm{m})$ of the hot absorber $\left(1100^{\circ} \mathrm{C}\right)$ back onto it without reducing solar transmittance. The examined transparent conductive oxides (TCO) involve a high solar absorptance, inhibiting their use in high-concentration solar systems. Although conventional dielectric interference filters have a low solar absorption, the reflection of solar radiation which comes from various directions is too high. It was found that only rugate filters fulfill the requirements for operation under highflux solar radiation with different incident angles. A thermodynamic qualification simulation of the rugate coating on a window of a flat-plate receiver showed a reduction of almost $175 \mathrm{~K}$ in mean window temperature and $11 \%$ in receiver losses compared to an uncoated window. Finally, a first $25-\mu \mathrm{m}$ thick rugate filter was manufactured and optically characterized. The issue of this paper is to share the work done on the choice of filter type, filter design, thermodynamic evaluation, and deposition experiments.
\end{abstract}

\section{INTRODUCTION}

In central receiver technology, two-axis tracking heliostats concentrate solar radiation onto the receiver which is located on top of a tower. The high solar concentration factors between 200 and 1000 enable efficient operation of high-temperature receivers which normally guarantee high cycle efficiencies. An example is the pressurized volumetric receiver (for example REFOS [1, 2], DIAPR [3, 4]) which integrates the solar energy directly into the topping Brayton cycle of a combined cycle. These receivers have a transparent window to separate the pressurized air from ambient. Fig. 1 shows details of the REFOS-type receiver. The secondary concentrator protects the receiver housing and further concentrates the incident radiation, collected by the heliostat field. Concentrated sunlight goes through the fused-silica window and then is absorbed in the volumetric absorber. Compressed air of the gas turbine compressor enters the receiver and is heated while flowing through the hot volumetric absorber structure. The heated air exits the receiver module through the air outlet, which is connected either to a further receiver module for additional solar heating or to the combustion chamber of the gas turbine.

Open volumetric or tubular receivers may also be equipped with a window to separate the receiver working medium from ambient or merely to reduce losses. Frequently, fused silica, having a high solar transmittance, low expansion coefficient and hence good shock resistance, is used as window material. 


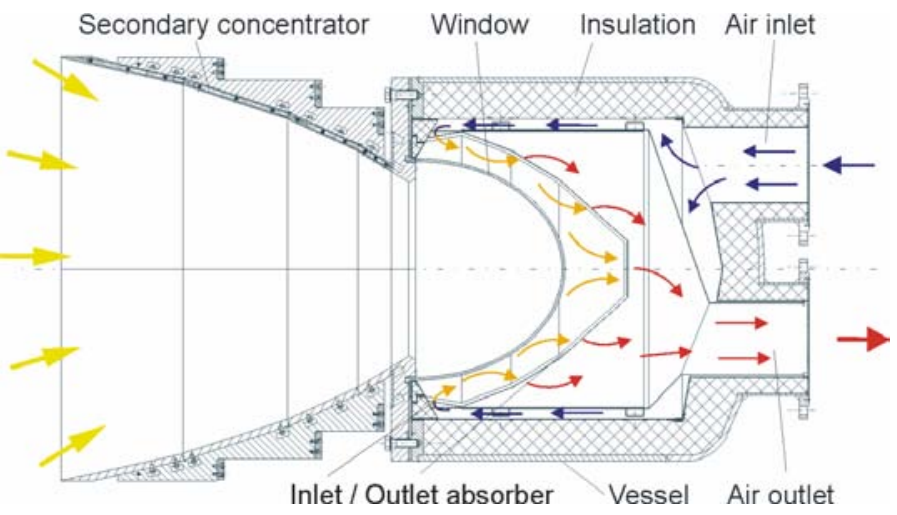

Fig. 1: Pressurized high-temperature receiver (REFOS)

One major challenge in high-temperature pressurized volumetric air receiver technology with outlet temperatures over $800^{\circ} \mathrm{C}$ is the excessive heating of the fused-silica window. Particularly at high temperatures, the glass may recrystallize into the more stable, crystalline $\beta$-cristobalite structure. If the window cools down below $250^{\circ} \mathrm{C}$ during cloudy transients or at night, the $\beta$-cristobalite becomes $\alpha$-cristobalite. This transformation is critical, because the different specific volumes of the two crystalline phases may cause chipping of the quartz glass leading to degradation of the receiver window. The process of recrystallization is accelerated at high temperatures and in atmospheres with nucleus-forming contaminants like alkali or earth alkali ions $[5,6]$. For an enduring, safe operation of pressurized volumetric receivers, a maximal fused-silica temperature of $800^{\circ} \mathrm{C}$ is considered tolerable.

One approach to avoid window overheating is using active cooling measures, e.g. air-jet cooling on the window outside [7, 8] or gap cooling on the window inside [9]. The active measures involve additional components like blower, air distribution systems, and nozzles in air-jet cooling or a second window and an air distribution ring in gap cooling. Furthermore, active cooling systems usually affect system efficiency.

In contrast to active measures, passive measures reduce the heat input and hence avoid excessive window heating. Infraredreflective (IRR), solar-transparent, high-temperature stable coatings on fused silica belong to the passive measures.

Visibly transparent IRR coatings are widely used. Example applications are solar-control and low-emissivity (low-e) coatings used in architectural glazing. The simplest coating for this purpose is made from thin metal films packaged between dielectric layers as blocking layers to avoid oxidation processes. The metal layers yield a reflection of the infrared (IR) region while, due to their very small thickness, the films are still mostly transparent in the visible region. IRR coatings are also increasingly used in the automotive sector to limit heating of vehicles with large window areas. Coatings for energy-saving lamps are also often based on metallic layers (silver or aluminum films packaged within blocking layers).
However, metal films do not seem suitable for the use in solar thermal technology where receiver windows might reach operating temperatures above $900^{\circ} \mathrm{C}$. Thus, the use of TCO coatings and dielectric interference filters in different embodiments (conventional, rugate) are more promising approaches.

The use of coatings on glass is steadily increasing in concentrated solar thermal technology. Today, anti-reflective coatings are frequently used. There is research and development on other kinds of filters for high-flux solar thermal applications, for example on spectrally selective filters (beam splitters) [10] or IRR filters (this paper).

\section{THE IDEAL FILTER AND OPERATING PRINCIPLE}

Fig. 2 shows a section of the geometric receiver configuration and the coating operation principle. The fusedsilica window is arranged in front of the absorber $\left(1100^{\circ} \mathrm{C}\right)$. The coating is deposited on the window side facing the absorber surface. The concentrated solar radiation transmits the fused-silica substrate and coating and is absorbed in the absorber structure. An ideal coating should not significantly reduce transmittance of the highly concentrated solar radiation and reflect a maximum part of the thermal spectrum emitted from the hot absorber back onto it. Calculations showed that the wavelength cutoff should be about $2.5 \mu \mathrm{m}$.

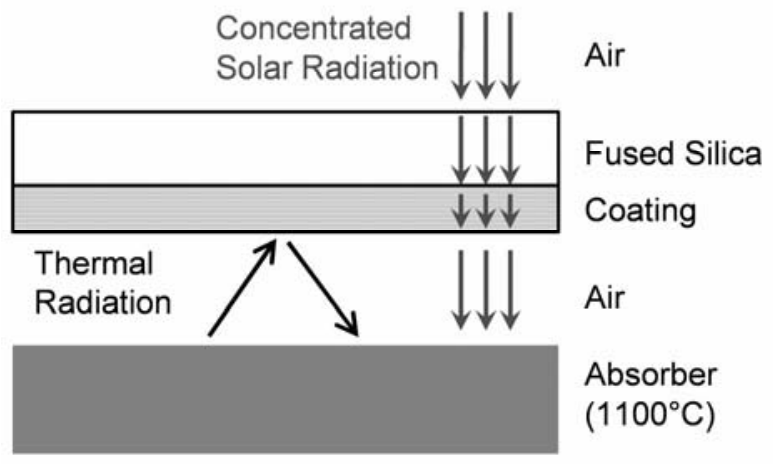

Fig. 2: Geometric receiver configuration (flat plate) and coating operation principle

For application on the window of a high-temperature highflux solar receiver, the coating must fulfill the following optical, thermal, and mechanical requirements.

The optimal wavelength cutoff is about $2.5 \mu \mathrm{m}$. Solar transmittance $(\lambda<2.5 \mu \mathrm{m})$ must not be decreased compared to the uncoated substrate to not lose solar radiation. Due to the high solar flux densities, it is also essential that the absorptance of the solar spectrum $(\lambda<2.5 \mu \mathrm{m})$ is not increased. Otherwise heat input by solar absorption increases the temperature prohibitively. To reflect the absorber radiation, reflectance for wavelengths $\lambda>2.5 \mu \mathrm{m}$ should be maximal.

For the solar receiver application, the coating must be heatresistant at least up to $800^{\circ} \mathrm{C}$ and show long-term stability, also under cyclic heating. Additionally, the coating must mechanically resist window handling and cleaning and should 
not affect the fused-silica structure. For example, it should not accelerate cristobalite formation.

\section{EXAMINED COATING TYPES}

The main tasks in designing optical filters are the selection of appropriate materials not only depending on optical properties but also on mechanical requirements and thus finding a useful compromise between technological feasibility and optical performance. To realize a coating for a solar receiver window using thin film technologies, different approaches are possible.

\subsection{Transparent Conductive Oxide Filter (TCO)}

The TCO filter working principle is spectral excitation. TCO coatings are wide-gap semiconductors $(\sim 3 \mathrm{eV}$ and above) which are highly doped to shift the plasma frequency $\omega_{p}$ in order to get metal-like conductivity due to a high degree of free charge carriers. At the same time, the transparency for frequencies higher than $\omega_{p}$ is maintained. Furthermore the wide band gap avoids excitation of charge carriers into the conductive band which would yield to absorption within the visible region. Thus the functionality can be considered a material property.

TCO films are widely used as transparent electrodes for solar cells as well as in the display technology to contact liquid crystal displays (LCD) or organic light-emitting diodes (OLED) [11-13]. Various deposition techniques have recently been used to prepare TCO thin-films, namely physical vapor phase deposition (PVD) techniques such as sputtering [14], evaporation [15], ion implating [16] as well as Sol-Gel processes $[17,18]$. However, some of them need additional heating of the substrate during deposition.

Due to the combination of visible transparency and metallic reflection, TCO materials could thus be suitable for use in a solar receiver, assuming that the thermal stability can be guaranteed. This might be feasible using packaging techniques for the TCO layer. However, the use of TCO materials for such applications is not known to the authors.

\subsection{Interference Filter}

In contrast to TCO filters, the interference filters solely function by interference effects which are created using a sequence of layers made from at least two different materials. When using dielectric materials without absorption, filters completely transparent for the solar radiation might be possible.

Regarding the optical dispersion of the materials used, a set of film thicknesses which yield to spectral regions of constructive or destructive interference can be designed to obtain anti-reflective coatings (destructive in reflection) or mirrors (constructive in reflection), for example. However, the optical performance of the interference filter improves with the number of layers and total thickness.

One major drawback of these conventional filters is an effect called angular shift which results from the law of refraction where reflectance and transmittance spectra shift with change of the viewing angle. However, the absence of absorption of the dielectric materials used is highly beneficial in the solar receiver application.

3.2.1 Conventional Interference Filter. Conventional interference filters can be produced by the same processes as for the deposition of TCO materials using Sol-Gel or PVD processes like plasma enhanced evaporation or sputtering processes for high-end applications. Among these, especially magnetron-sputtering processes have been qualified for costefficient and precise coating of large area substrates. Glass substrates up to approximately $6 \mathrm{~m} \times 3 \mathrm{~m}$ size or even plastic foils of $2.5 \mathrm{~m}$ width are coated in highly efficient on-the-fly or roll-to-roll sputtering processes.

The design of conventional interference filters is mostly done using computer programs which are capable of calculating the theoretical spectra resulting from a given layer stack made from known material dispersions. These programs are fed with a target spectrum. An optimization algorithm then varies the layer sequence and layer thicknesses, calculates the theoretical spectra, compares them to the target and minimizes the discrepancy between target and theory until a sufficient correspondence is reached. The theory behind these processes is well understood and the different design strategies have intensively been studied building the basics for modern thin film design [19].

Conventional interference filters are used in a large variety of applications, e.g. as simple anti-reflective coatings [20, 21], mirrors for laser applications [22] or filters (band, cut-off, neutral density (ND)) for spectroscopic applications, in measurement devices or cameras [23]. Furthermore, dielectric (or dichroic) coatings with complex selectively reflecting properties are used as heat stable color filters for beamers or on projection displays for contrast enhancement as well as for transparent projection combiners in Head-Up-Displays (HUD) $[24,25]$.

3.2.2 Rugate Interference Filter. Having a low absorption, conventional interference filters seem to be a good basis for the development of high-performance IRR filters for application in solar receivers. Thus, a new technology for the fabrication of rugate filters (filters with "corrugated" index profiles) based on dielectric interference coatings was examined for a possible performance gain.

While conventional interference filters consist of only two materials (low- and high-refractive), rugate filters comprise a quasi continuous mixture of these two materials leading to a continuously modulated index of refraction [26]. Fig. 3 shows a comparison of exemplary index profiles and Fig. 4 the resulting reflection spectra of the two filter types. The rugate interference filter (right) shows that a simple apodization by tailoring the index profile (corrugation) leads to a suppression of ripples in the reflectance and transmittance spectra. 

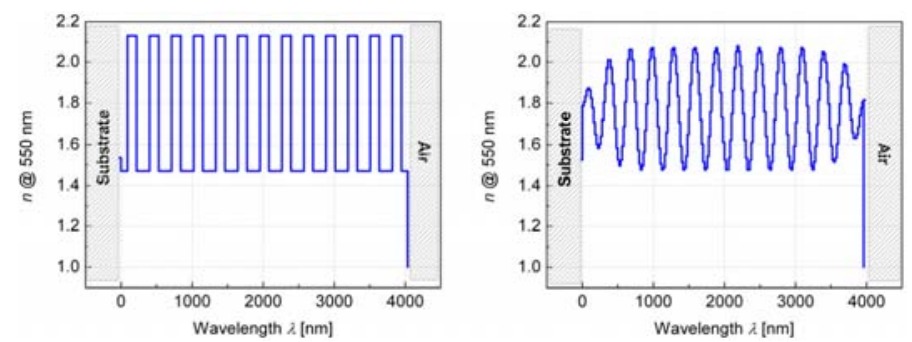

Fig. 3: Index profiles of conventional (left) and rugate filter (right) in comparison
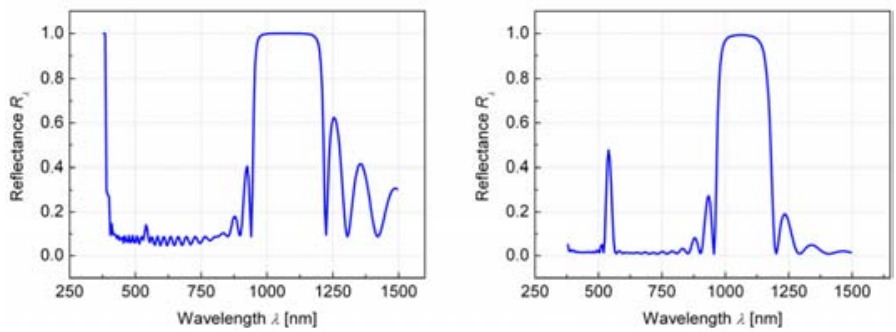

Fig. 4: Reflection spectra of conventional (left) and rugate filter (right) in comparison. The apodization leads to a suppression of ripples

Since the transmittance and the index profile of interference filters are interconnected via a Fourier transformation $[27,28]$, it is obvious that rugate filters reveal a better optical performance than conventional filters. The use of such a quasi-continuously modulated index of refraction is supposed to deliver several enhancements over the conventional approach. Some of them are:

- increased thermal stability (due to absence of internal interfaces and due to the mixtures itself)

- improved optical performance for oblique/angular-range filters

- improved optical performance even for normal incidence due to the possibility to use apodization techniques.

Since the filter components can no longer be deposited in sequence and instead must be deposited at the same time with varying fractions, the deposition process must be changed. Thus, process control becomes quite difficult and new technologies/procedures have to be evolved. A comparison between different processes for the deposition of rugate filters and a design approach are given in Janicki et al. [29].

In addition to the novelty of the process technology, there are no commercial design tools for rugate filters available yet. It can be assumed that as soon as software tools become available, the performance of rugate filters can even be further improved.

\section{THERMODYNAMIC EVALUATION}

Table 1 gives an overview of the filters evaluated in this paper. The uncoated GE 214 substrate is the status quo, the ideal filter shows the maximal potential, and the TCO and conventional/rugate interference filters show what can be expected from the individual technologies.

Table 1: Substrate and filter details

\begin{tabular}{|c|c|c|}
\hline Abbreviation & Substrate & Coating \\
\hline GE 214 substrate & GE 214 & $\begin{array}{l}\text { None. Substrate: } 5-\mathrm{mm} \text { fused silica } \\
\text { (GE 214, fire polished) }\end{array}$ \\
\hline Ideal filter & GE 214 & $\begin{array}{c}\text { Ideal edge filter without changing } \\
\text { substrate for } \lambda<2,5 \mu \mathrm{m} .99 .5 \% \text { re-flect. } \\
\text { and } 0.5 \% \text { absorpt. for } \lambda>2,5 \mu \mathrm{m}\end{array}$ \\
\hline TCO filter & GE 214 & $\begin{array}{l}\text { Two TCO layers of } \mathrm{ZnO} \text { :Al with di- } \\
\text { electric cover/packaging layer }\end{array}$ \\
\hline $\begin{array}{l}\text { Conventional } \\
\text { interference filter }\end{array}$ & GE 214 & $\begin{array}{l}\mathrm{SiO}_{2} \text { and } \mathrm{Ta}_{2} \mathrm{O}_{5} \\
(70 \text { layers, } \sim 6 \mu \mathrm{m})\end{array}$ \\
\hline $\begin{array}{l}\text { Rugate } \\
\text { interference filter }\end{array}$ & GE 214 & $\begin{array}{c}\mathrm{SiO}_{2} \text { and } \mathrm{Ta}_{2} \mathrm{O}_{5} \\
(\sim 1000 \text { virtual layers, } \sim 40 \mu \mathrm{m})\end{array}$ \\
\hline
\end{tabular}

\subsection{Radiation Model}

The performance of the individual filter designs on window temperature and receiver loss is evaluated using a radiation model developed at DLR. The radiative heat transfer between the absorber, semi-transparent window and ambient is modeled by applying the enclosure method (zone method), which was introduced by Hottel $[30,31]$. To model the nongray spectral properties, up to 40 wavelength bands were used. The flat-plate model comprises of four discretization surfaces (one per surface zone: ambient, window outside, window inside, and ambient). The REFOS receiver model is discretized in 755 surfaces. Absorbed solar radiation is modeled as source term and is assigned coated and uncoated window side one half each. Model boundary conditions can be found in sections 5 and 6. More details of the model can be found in [9].

\subsection{Coating Evaluation Criteria}

From a thermodynamic point of view, two criteria are relevant for the coating evaluation on a solar receiver window. The first criterion is the reduction of the fused-silica temperature compared to an uncoated substrate. The temperature of the coated fused silica is essentially determined by absorption of solar and thermal radiation.

The second criterion for the coating evaluation is the reduction of receiver losses to ambient. The losses are composed of solar radiation reflected on the window surface and thermal radiation emitted by window and absorber. For comparison, the receiver losses listed in the tables are normalized with the value of the uncoated receiver (GE 214 substrate only). 


\section{FILTER EVALUATION RESULTS OF FLAT RECEIVERS}

The flat-plate receiver calculations serve to easily compare the different filter types without focus on a special configuration. A sketch of the flat-plate configuration can be seen in Fig. 2. The boundary conditions of these simulations are listed in Table 2 . The assumption of diffusely incident solar radiation is conservative, since reflectance and absorptance usually rise with rising incidence angle.

\section{Table 2: Boundary conditions for flat plate receiver}

\begin{tabular}{l|l}
\hline Boundary Condition & \multicolumn{1}{c}{ Value } \\
\hline Geometry & $\begin{array}{l}\text { Flat-plate absorber and 5-mm thick window } \\
\text { (infinite extension). 4 discretization surfaces }\end{array}$ \\
Substrate and coating & $\begin{array}{l}\text { Spectra from complex refractive indices } \\
\text { Solar: Diffuse incidence }\end{array}$ \\
Incidence angles & Thermal: Diffuse incidence \\
Solar flux density & $650 \mathrm{~kW} / \mathrm{m}^{2}$ (homogenous) \\
Absorber temperature & $1100^{\circ} \mathrm{C}$ (homogenous) \\
Ambient temperature & $25^{\circ} \mathrm{C}$ \\
Convection & No convective heat flows on window \\
\hline
\end{tabular}

\subsection{The Ideal Filter}

Fig. 5, first line, shows the GE 214 fused-silica spectra under diffuse radiation, and the solar and $1100^{\circ} \mathrm{C}$-blackbody spectra. Fig. 6 left, first and second bar, visualizes the solar weighted absorptance, reflectance, and transmittance of the uncoated 5-mm thick GE 214 fused-silica substrate and the substrate coated with an ideal filter, respectively (diffuse radiation). The solar spectrum (air mass 1.5) includes spectral absorption in the heliostat surface facets. Solar absorptance and reflectance is slightly increased in the ideal filter because a small part of the spectrum lies above $2.5 \mu \mathrm{m}$.

Fig. 6 right, visualizes the same for a $1100^{\circ} \mathrm{C}$-blackbody weighting. According to Fig. 6 right, a $1100^{\circ} \mathrm{C}$-blackbody spectrum is transmitted to $54.9 \%$, reflected to $12.5 \%$ and absorbed to $32.6 \%$ by the uncoated fused-silica substrate. An ideal filter with cutoff wavelength of $\lambda=2.5 \mu \mathrm{m}$ almost does not change solar transmittance, but reduces the blackbodyweighted transmittance to $36.5 \%$, increases reflectance up to $63 \%$ and thus reduces absorptance to less than $1 \%$. Hence, an ideal filter minimizes both glass temperatures and receiver losses. The filter reflectance in the range of $2.5 \mu \mathrm{m}$ to $3.5 \mu \mathrm{m}$ reduces thermal transmission losses while the reflectance for wavelengths higher than $3.5 \mu \mathrm{m}$ reduces absorption of thermal radiation.

For the flat-plate configuration, an ideal filter reduces the window temperatures by $370 \mathrm{~K}$ or $390 \mathrm{~K}$ (mean and maximum temperature, respectively). The mean window temperature is averaged over window inside and outside. The maximum temperature is located on the window inside. The receiver losses are reduced by $28 \%$. Table 3 lists more details.

\subsection{Transparent Conductive Oxide Filter (TCO)}

Several exemplary designs were done using material data from $\mathrm{ZnO}$ :Al TCO films developed for high transparency up to $780 \mathrm{~nm}$ and improved conductivity. The material data were acquired using multi-angle spectral ellipsometry within the spectral region from 300 to $850 \mathrm{~nm}$. Material properties above $850 \mathrm{~nm}$ were extrapolated.

A twin-layer $\mathrm{ZnO}: \mathrm{Al}$ film embedded in three dielectric layers is chosen for thermodynamic evaluation. The spectra under diffuse radiation is shown in Fig. 5, line 2. The double layer arrangement was used to get better suppression of transmittance within the IR part of the spectrum while keeping high transparency within the visible spectrum. Furthermore, due to the high operating temperatures, a blocking layer to avoid a degradation of the films by oxidation is needed.

However, the absorptance spectrum shows a relatively high absorption even within the solar range, where $18.2 \%$ of the concentrated solar radiation is absorbed in the coated window (see Fig. 6 left). This leads to a high heat input, increasing mean window temperatures to $1068^{\circ} \mathrm{C}$, i.e. approximately $250 \mathrm{~K}$ above the temperature of an uncoated window. Hence, this coating is unsuitable for the solar highflux application. The reason for the high solar absorptance might be the high plasma-frequency considering the targeted application for the evaluated layer. A material development using different doping grades or other TCO materials might lead to a more suitable optical performance. However, a significant additional effort to cover the TCO materials and make them thermally stable would be needed. Furthermore, it is questionable whether a suitable packaging is feasible at all. Thus, the time consuming and difficult task of material development was not further followed.

\subsection{Conventional Interference Filter}

Interference filters of up to 100 layers with a thickness of about $10 \mu \mathrm{m}$ were designed using commercially available thin film software tools. The absorptance of the dielectric materials $\left(\mathrm{SiO}_{2}\right.$ and $\left.\mathrm{Ta}_{2} \mathrm{O}_{5}\right)$ is as low as expected, leading to only $1.5 \%$ absorption of the solar radiation (see Fig. 6 left). The strong increase at about $3.5 \mu \mathrm{m}$ is mainly due to the substrate absorption.

However, Fig. 7 shows the large impact of the angular shift onto the filter performance. In the solar range, the increasing reflectance with increasing angle of incidence can be seen. In addition, even for normal incidence, it was not possible to reduce the ripples in reflectance. This problem remained, even by use of more layers and larger filter thicknesses. Although, compared to the uncoated window, the temperature was reduced slightly by about $35 \mathrm{~K}$, as already $28.2 \%$ of the incident solar radiation is reflected off the window. This leads to too high receiver losses which do not compensate for the small temperature reduction. For comparison, you may also see Fig. 5 and 6, and Table 3. 

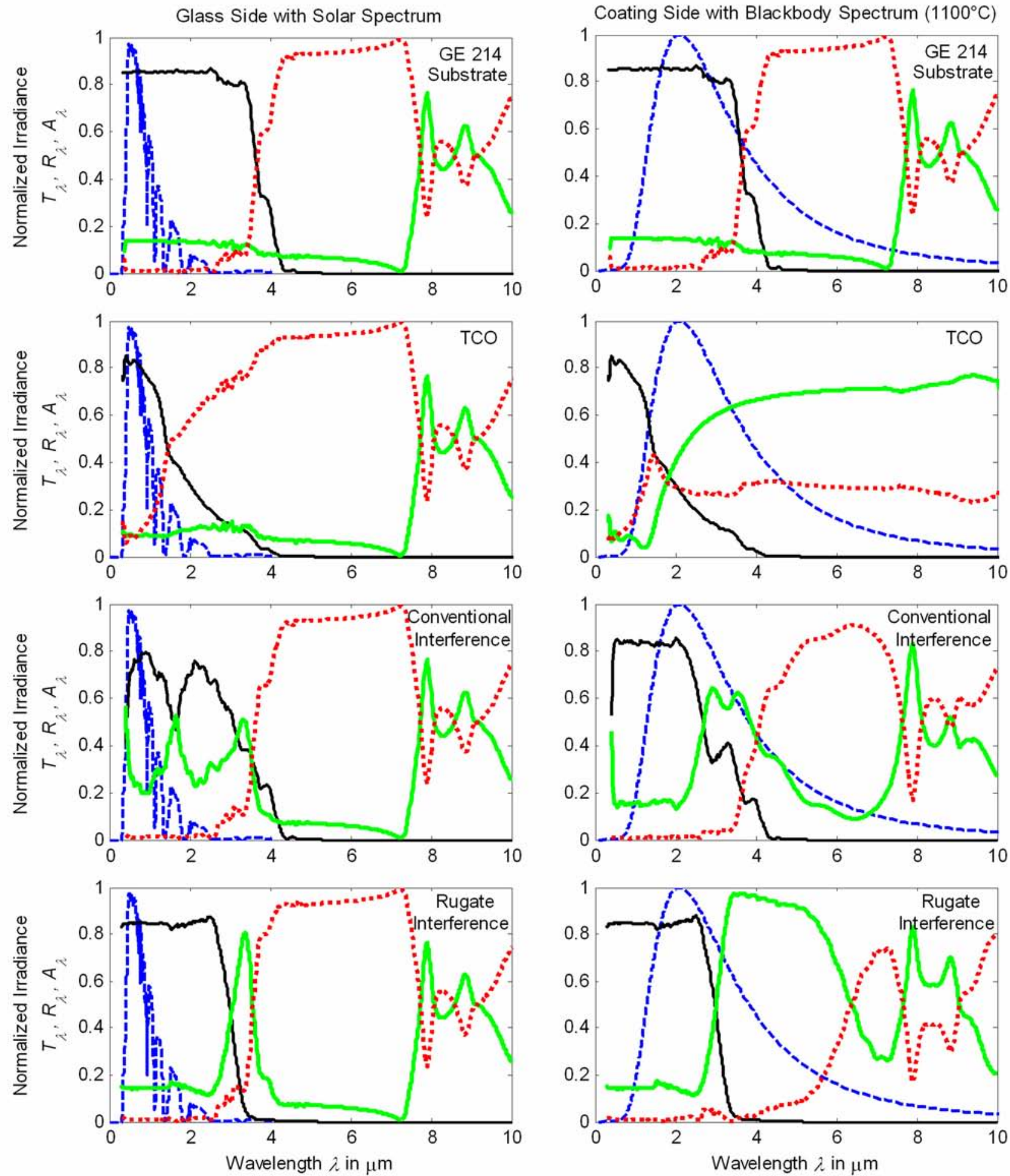

----- Spectrum $\longrightarrow T_{\lambda}-R_{\lambda} \ldots \ldots A_{\lambda}$

Fig. 5: Absorptance, reflectance, and transmittance spectra of the uncoated GE 214 substrate, TCO filter system, conventional and rugate interference filter for a flat receiver under diffuse radiation. Glass side, left; coating side, right. Filter details see Table 1 

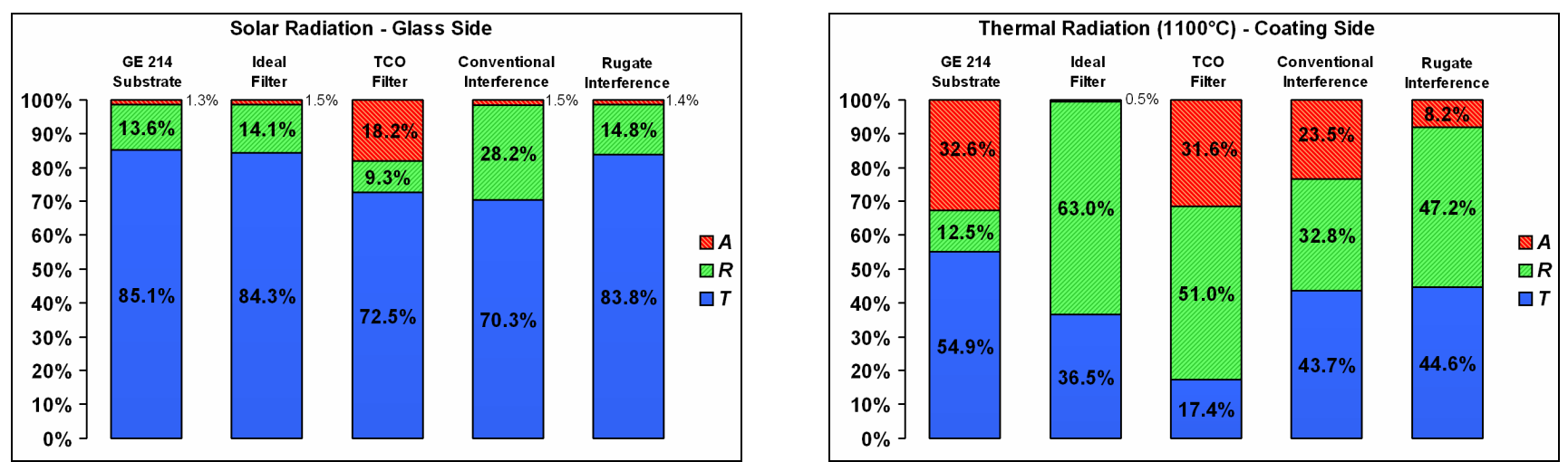

Fig. 6: Spectrally weighted absorptance, reflectance, and transmittance of the uncoated GE 214 substrate, ideal filter, TCO filter system, conventional and rugate interference filter. Solar spectrum weighting (left), $1100^{\circ} \mathrm{C}$ blackbody spectrum weighting (right). Incidence from glass side. Filter details see Table 1

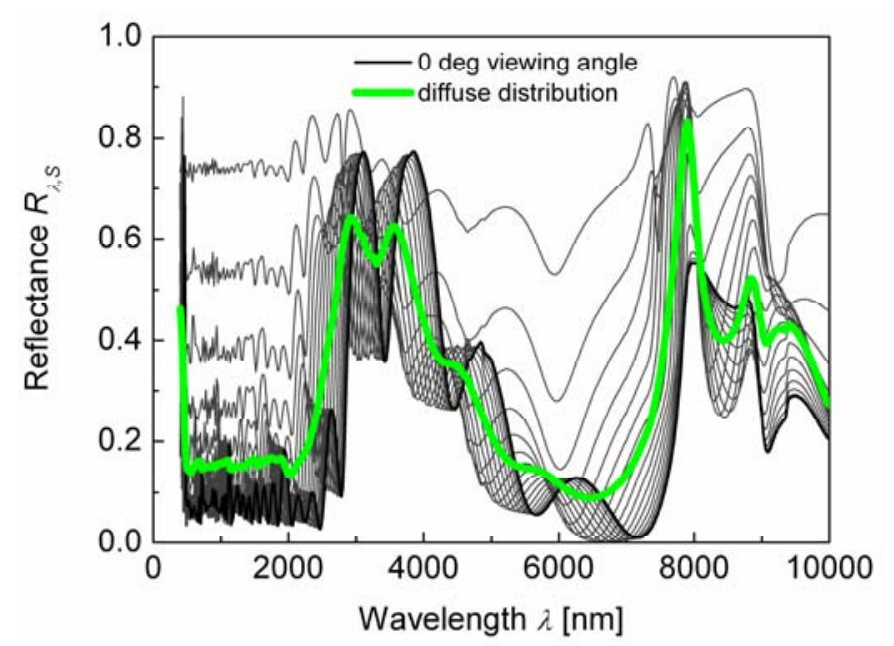

Fig. 7: Spectral reflection for different viewing angles $\left(0 . .85^{\circ}\right)$ of a conventional interference filter (thickness $6 \mu \mathrm{m}, 70$ layers, $\mathrm{SiO}_{2}$ and $\mathrm{Ta}_{2} \mathrm{O}_{5}, \mathrm{GE} 214$ fused silica substrate, incidence from coating side)

\subsection{Rugate Interference Filter}

Fig. 8 shows the reflectance spectrum of a $40-\mu \mathrm{m}$ thick IRR rugate filter. The solar absorptance is small (1.4\%, Fig. 6 left). The reflectance in the solar range is also significantly reduced by half compared to the conventional approach (14.8\%, Fig. 6 left). Furthermore, the angular dependency is reduced as well. The upper reflectance band range is $6.5 \mu \mathrm{m}$, the band is more pronounced as in the conventional approach and the filter also works for larger angles of incidence. This results in a reflectance of the $1100^{\circ} \mathrm{C}$-blackbody spectrum of $47.2 \%$ (Fig. 6 right). The mean/maximal window temperature can be reduced by $174 \mathrm{~K} / 184 \mathrm{~K}$, respectively compared to the uncoated substrate. The receiver losses decreases $11 \%$ (see Table 3).

Of course, this filter can not be directly compared to the conventional approach of section 5.3 due to the discrepancy

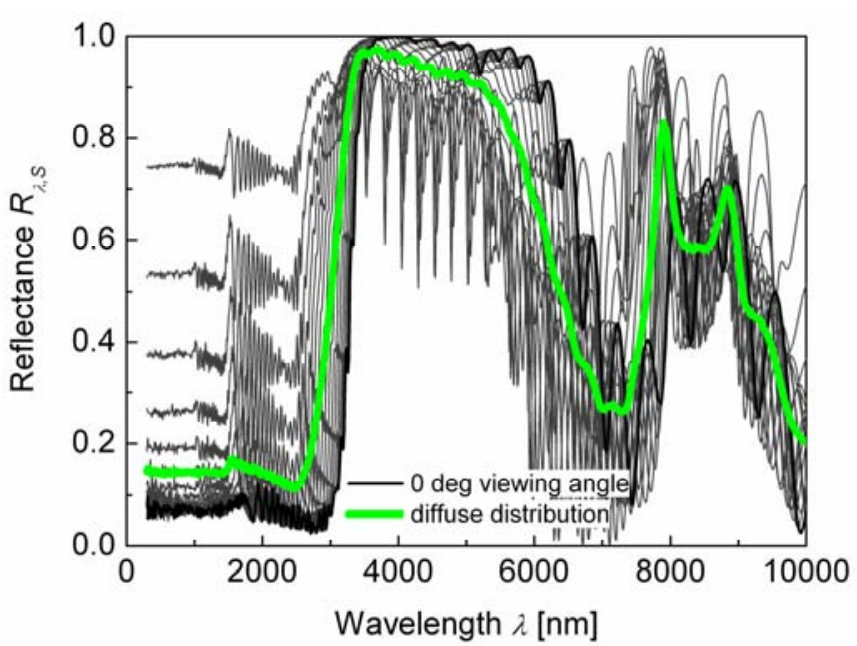

Fig. 8: Spectral reflection for different viewing angles $\left(0 . .85^{\circ}\right)$ of a rugate interference filter (thickness $40 \mu \mathrm{m}, \sim 1000$ virtual layers, $\mathrm{SiO}_{2}$ and $\mathrm{Ta}_{2} \mathrm{O}_{5}$, GE214 fused silica substrate, incidence from coating side)

within the technological effort (5 against $40 \mu \mathrm{m})$. However, even thicker conventional filters still reveal the discussed problems. Additionally, rugate filters should provide a better temperature stability.

For the high-flux high-temperature solar receiver window, rugate interference filters seem to perform best.

Table 3: Evaluation results of flat-plate receiver

\begin{tabular}{|c|c|c|c|}
\hline Abbreviation & $\begin{array}{c}\text { Window } \\
\text { mean }\end{array}$ & $\begin{array}{l}\text { p. in }{ }^{\circ} \mathrm{C} \\
\max \end{array}$ & $\begin{array}{c}\text { Normalized } \\
\text { Receiver Loss [-] }\end{array}$ \\
\hline GE 214 substrate & 821 & 850 & 1.00 \\
\hline Ideal filter & 450 & 459 & 0.72 \\
\hline TCO filter & 1068 & 1117 & 0.92 \\
\hline Conv. interference filter & 787 & 815 & 1.30 \\
\hline Rugate interference filter & 647 & 666 & 0.89 \\
\hline
\end{tabular}




\section{RUGATE FILTER EVALUATION RESULT OF REFOS- TYPE RECEIVER}

In this section, the simulations for a real high-temperature receiver geometry are presented, the REFOS receiver. Fig. 9 shows its geometry and heat flows. Table 4 lists the boundary conditions used for the simulations. Due to the cavity shape and by using incidence angles from ray-tracing, the solar incidence angles change significantly compared to section 5 (assumption of a diffusely radiated flat plate) and hence reflectance should be reduced. Radiation heat exchange between absorber, window, and ambient is also influenced by the cavity geometry. Heat exchange by thermal radiation is assumed to be diffuse. In addition, convective heat flows due to free convection on the window outside and a forced convection due to the hot absorber flow on the window inside are considered. The thermodynamic radiation model is discretized into 755 surface elements.

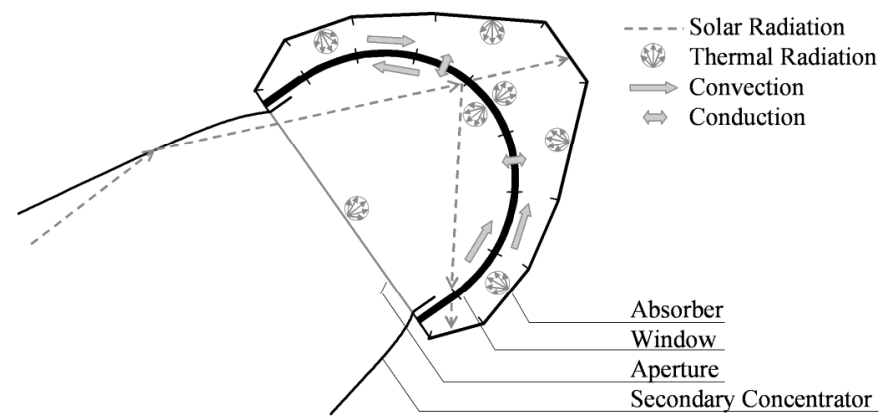

Fig. 9: Thermodynamic model of REFOS receiver

Simulations with the uncoated window confirmed that the amount of solar radiation reflected off the concave window is reduced to $2 \%$ of the incident power (compared to $13.6 \%$ for the flat plate under diffuse radiation). However, the temperature of the window top reaches $988^{\circ} \mathrm{C}$ due to its exposed position to the absorber (see Table 5). The receiver losses are $11 \%$ of the incident power (secondary outlet plane power is $100 \%=464 \mathrm{~kW}$ ). Receiver simulations with TCO filters are not presented here, because TCO filters already were considered as unsuitable in section 5 .

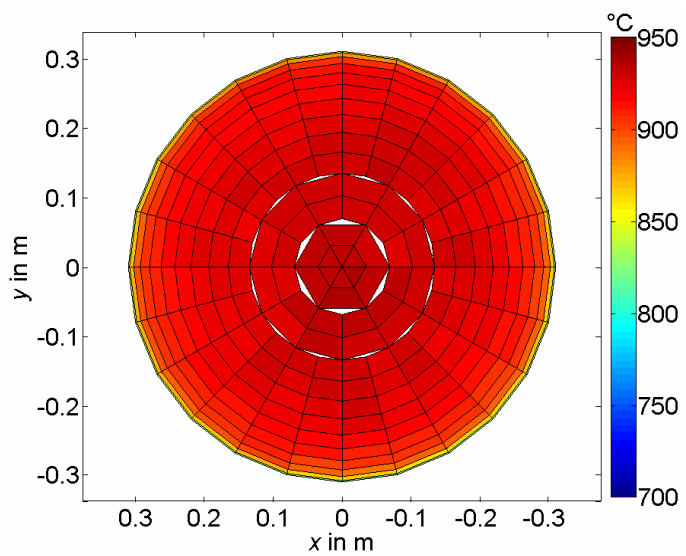

Table 4: Boundary conditions for REFOS receiver

\begin{tabular}{l|l}
\hline Boundary Condition & \multicolumn{1}{c}{ Value } \\
\hline Geometry & $\begin{array}{l}\text { 3D REFOS receiver geometry, 5-mm thick } \\
\text { window (see Fig. 9). 755 discretization surf. }\end{array}$ \\
Substrate and coating & $\begin{array}{l}\text { Spectra from complex refractive indices } \\
\text { Solar: } \quad \text { Traced rays depending on heliostat }\end{array}$ \\
Incidence angles & $\begin{array}{l}\text { Thermal: Diffuse incidence } \\
\text { Solar radiation and flux }\end{array}$ \\
density & $\begin{array}{l}\text { HELIOS simulation: March 21, 12:00h UTC, } \\
\text { distributed (mean: } 570 \mathrm{~kW} / \mathrm{m}^{2} \text { ). }\end{array}$ \\
& On secondary outlet plane: $\sim 464 \mathrm{~kW}$ \\
Absorber temperature & $1100^{\circ} \mathrm{C}$ (except for inlet absorber ring: $900^{\circ} \mathrm{C}$ ) \\
Ambient temperature & $25^{\circ} \mathrm{C}$ \\
\hline Convection & Window outside: Free convection \\
\hline
\end{tabular}

\subsection{The Ideal Filter}

For the REFOS-type receiver, the ideal filter reduces maximum window temperatures by almost $210 \mathrm{~K}$ compared to the uncoated window. Losses were reduced by $25 \%$. Due to the altered geometry, the reduction potentials are smaller compared to the flat plate case of section 5 .

\subsection{Conventional Interference Filter}

The conventional interference filter doubles the receiver losses compared to the uncoated window and reduces maximum temperatures only by $29 \mathrm{~K}$. Thus, it is unsuitable for this application.

\subsection{Rugate Interference Filter}

The rugate interference filter reduces maximum temperatures by $78 \mathrm{~K}$, mean temperatures by $65 \mathrm{~K}$. Fig. 10 compares the front views of the temperature distributions on the window outside for the uncoated substrate and the rugate interference filter. The receiver losses are $4 \%$ smaller than in the uncoated case.

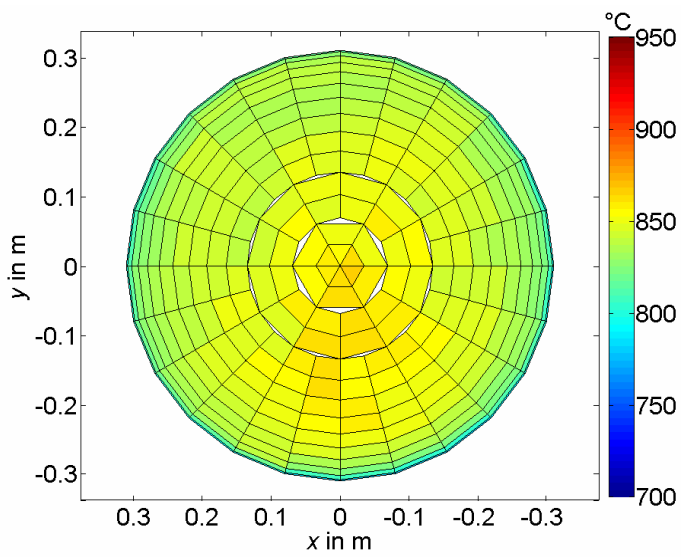

Fig. 10: Comparison of temperatures on window outside without coating (left) and with rugate interference filter (right) for $1100^{\circ} \mathrm{C}$ absorber temperatures (front views). More details in Tables 4 and 5 
As can be seen in Table 5, the goal of a maximum allowable fused-silica window temperature of $800^{\circ} \mathrm{C}$ has not been reached totally. Assuming a lower mean absorber temperature of $1000^{\circ} \mathrm{C}$, simulations result in mean window temperatures of $797^{\circ} \mathrm{C}$, and maximum (internal) temperatures of $860^{\circ} \mathrm{C}$. Hence, the maximum temperature level would be exceeded only by the hottest spot of the window inside. Mean temperatures would be tolerable with the designed rugate filter. However, work on rugate filter design should be continued in future.

\section{Table 5: Evaluation results of REFOS-type receiver}

\begin{tabular}{l|cc|c}
\hline Abbreviation & \multicolumn{2}{|c|}{ Window Temp. in ${ }^{\circ} \mathbf{C}$} & Normalized \\
mean & max & Receiver Loss [-] \\
\hline GE 214 substrate & 908 & 988 & 1.00 \\
Ideal filter & 745 & 779 & 0.75 \\
Conv. interference filter & 884 & 959 & 2.04 \\
Rugate interference filter & 843 & 910 & 0.96 \\
\hline
\end{tabular}

\section{FIRST RUGATE DEPOSITION EXPERIMENTS}

A first experimental filter was deposited within this work to test the technical feasibility of thick rugate filters. An IRR filter comprising a total thickness of about $25 \mu \mathrm{m}$ was designed by M. Lappschies of the Laserzentrum Hannover. Being thinner than the $40-\mu \mathrm{m}$ rugate presented above, it reduces the window temperatures only by 30 to $40 \mathrm{~K}$, but it still represents an enormous total thickness and thus a challenge for the deposition process.

The filter was deposited using $\mathrm{RF}$ (radio-frequency) magnetron co-sputtering techniques. $\mathrm{SiO}_{2}$ and $\mathrm{Ta}_{2} \mathrm{O}_{5}$ were sputtered simultaneously from two ceramic cathodes while the power and thus the deposition rate for each cathode was controlled individually in order to get the desired material mixtures. Regarding the absence of interface sections within the filter, this stationary co-sputtering process comprises a principle advantage over comparable dynamic coating processes. The stationary hold substrate allows a real codeposition from both sources where the two materials form a compound. In dynamic coating processes for example, the substrates are moved and very thin layers of each component are coated individually.

Fig. 11 shows the deposition plant developed at the Fraunhofer Institute IST. Two 4-inch round cathodes were used with a constant total power of 770 Watts. Working pressure was about $2.5 \mathrm{e}-3$ mbar with argon as process gas.

The complete deposition process of this rugate filter lasted 100 hours. Although deposition processes for complex filters of such type are normally controlled by in-situ monitoring techniques to improve the filter performance, this evaluation study was carried out by time control using fixed deposition rates for each material mixture. Nevertheless, the overall spectral performance of the resulting rugate filter is fairly good compared to the targeted design spectra shown in Fig. 12.

This is clarified by comparing the resulting spectra with the target designs. In total, the agreement is very good except for two parts of the spectrum. The first deviation is the shift at about $0.4 \mu \mathrm{m}$ which is deriving from a rate drift during deposition. Thus, the lower-wavelength edge of the pass-band of the filter, located in the visible region shifts to higher wavelengths.

The second deviation from the target spectra can be identified around $2.7 \mu \mathrm{m}$. While the resulted reflectance is as low as in the design, the deviation of the transmittance and absorptance is due to absorption mechanisms. Considering the spectral region of the absorptance, it becomes apparent that this absorption is most probably produced by water inclusions within the filter deriving from coating defects of parasitic particles falling onto the substrate surface during the process. Although sputtering processes are normally known to produce very compact filters, these coating defects here could not completely be avoided.

Due to these deviations from the desired design and the resulting higher absorption in the solar range, the deposited filter did not reduce receiver window temperatures and losses (simulation). But taking into account the prototype character of this first experiment, it seems possible to deposit the simulated filter design on fused-silica to reduce receiver window temperature and losses in the future, as these problems are not a limitation of magnetron-sputtering in general. Anyhow, the magnetron sputtering process for the fabrication of rugate filters proved to be a very suitable technique for the preparation of high-temperature IRR coatings, since the asserted problems can easily be avoided using in-situ monitoring strategies and different sputter setups like a sputter-up geometry, where the substrates are directly located above the sputter sources or vertical arrangements as they are typical for conventional inline coating plants.
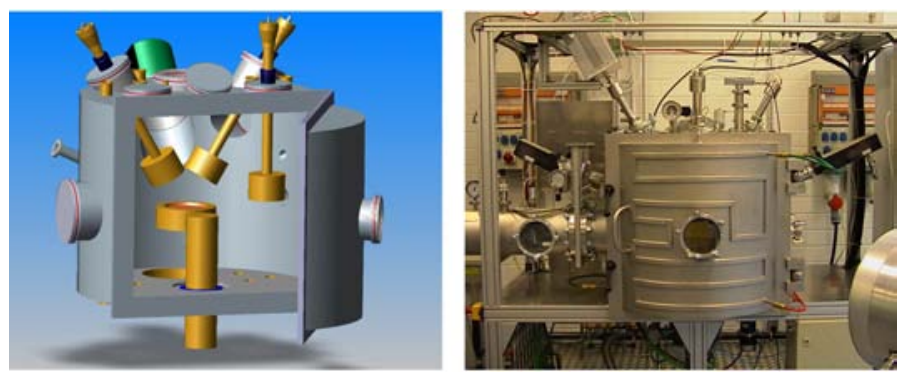

Fig. 11: RF-magnetron sputtering deposition plant. Schematic figure with the substrate in the center (left). Photo of the plant (right) 

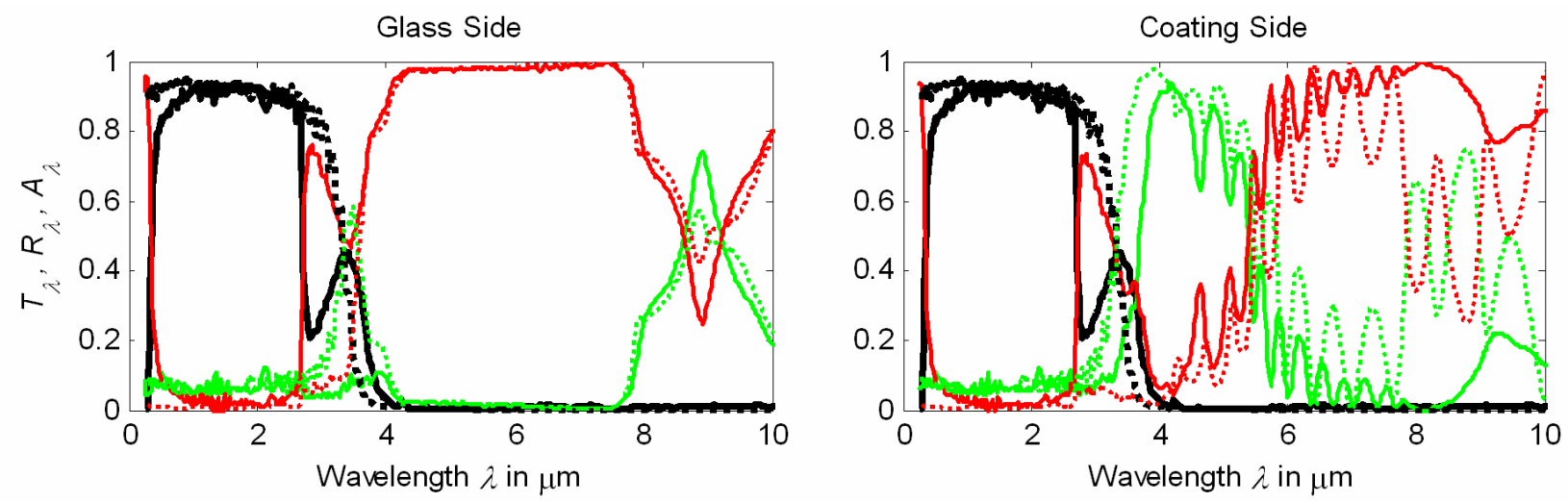

$-T_{\lambda, \text { meas }} \longrightarrow R_{\lambda, \text { meas }} \longrightarrow A_{\lambda, \text { meas }} \ldots \ldots . . T_{\lambda \text {,design }} \ldots \ldots \ldots . . . . R_{\lambda, \text { design }} \ldots \ldots \ldots . . . . A_{\lambda, \text { design }}$

Fig. 12: Measured and simulated absorption, reflection, and transmission spectra of deposited rugate filter (thickness $25 \mu \mathrm{m}, \sim 873$ virtual layers, $\mathrm{SiO}_{2}$ and $\mathrm{Ta}_{2} \mathrm{O}_{5}, \mathrm{GE214}$ fused silica substrate, normal incidence, room temperature)

\section{CONCLUSIONS}

Different types of IRR filters on a fused-silica window of a high-temperature high-flux solar receiver have been studied numerically. The examined TCO filters showed a high absorptance in the solar spectrum ( $\mathrm{ZnO}: \mathrm{Al}, 18 \%)$ leading to higher window temperatures than without coating. Thus, these TCO filters have been evaluated as unsuitable for this application.

It was shown that in contrast to TCO filters, conventional dielectric interference filters do not increase solar absorptance. However, they increase solar reflectance significantly for the sun rays coming in from different angles (up to $28.2 \%$ for the flat-plate receiver under diffuse solar radiation). The temperature reduction by conventional interference filters was only small and the increased receiver losses are not acceptable.

The examined rugate filter designs (thicker than the other filter types) showed both low solar absorptance and low solar reflectance, also under diffuse radiation. Simulations with the flat-plate receiver geometry showed that the mean/maximal temperature could be reduced by $174 \mathrm{~K} / 184 \mathrm{~K}$ and the receiver losses by $11 \%$, compared to the uncoated substrate $\left(1100^{\circ} \mathrm{C}\right.$ absorber temperature). The simulations for the REFOS receiver geometry resulted in lower window temperature reductions due to the cavity shape of the receiver. However, maximum temperature still could be decreased by $78 \mathrm{~K}$, mean temperature by $65 \mathrm{~K}\left(1100^{\circ} \mathrm{C}\right.$ absorber temperature). The receiver losses could be reduced by $4 \%$.

To gain experience in the deposition of thick rugate filters, a first $25-\mu \mathrm{m}$ thick filter was fabricated by $\mathrm{RF}$ magnetron sputtering. Except for two deviations (shift at about $0.4 \mu \mathrm{m}$ and water inclusions), the measured spectra fitted approximately the design spectra. However, these deviations led to higher receiver temperatures and losses than without coating (simulation). The deviations could be avoided using in-situ monitoring techniques and another deposition geometry. Taking the prototype character of this experiment into account, the filter deposition experiment was very promising.

Although there is still a lot of work left to test and apply IRR filters on large curved window surfaces, only rugate filters can meet the extraordinary optical and thermal requirements for high-flux high-temperature solar receiver windows and sun rays coming in from different angles.

\section{NOMENCLATURE}

$$
\begin{aligned}
A_{\lambda} & =\text { spectral absorptance }(-) \\
d & =\text { thickness }(\mathrm{nm}) \\
n & =\text { refractive index }(-) \\
R_{\lambda} & =\text { spectral reflectance }(-) \\
T_{\lambda} & =\text { spectral transmittance }(-) \\
\lambda & =\text { wavelength }(\mu \mathrm{m}) \\
\omega_{p} & =\text { plasma frequency }(1 / \mathrm{s})
\end{aligned}
$$

Subscripts and Superscripts

$\mathrm{S}$ = coating side

\section{Abbreviations}

DIAPR Directly Irradiated Annular Pressurized Receiver

DLR Deutsches Zentrum für Luft- und Raumfahrt (German Aerospace Center)

IR Infrared

IRR Infrared Reflective

REFOS Receiver for Solar Fossil Power Plants

RF Radio Frequency

TCO Transparent Conductive Oxides

\section{ACKNOWLEDGMENTS}

Financial support from the German Federal Ministry for the Environment, Nature Conservation and Nuclear Safety (CoMinit Contract 16UM0017) is gratefully acknowledged. 


\section{REFERENCES}

[1] Buck, R., Bräuning, T., Denk, T., Pfänder, M., Schwarzbözl, P., Téllez, F., 2002, "Solar-Hybrid Gas Turbine-based Power Tower Systems (REFOS)", J. Sol. Energy Eng., vol. 124, no. 1, pp .2-9.

[2] Heller, P., Pfänder, M., Denk, T., Téllez, F., Valverde, A., Fernandez, J., Ring, A., 2004, "Test and Evaluation of a Solar Powered Gas Turbine System", Solar Energy, vol. 80, no. 10, pp. 1225-1230.

[3] Karni, J., Kribus, A., Doron, P., Rubin, R., Fiterman, A., Sagie, D., 1997, "The DIAPR: A High-Pressure, HighTemperature Solar Receiver", Journal of Solar Energy Engineering, vol. 119, pp. 74-78.

[4] Kribus, A., Doron, P., Rubin, R., Reuven, R., Taragan, E., Duchan, S., Karni, J.: "Performance of the DirectlyIrradiated Annular Pressurized Receiver (DIAPR) Operating at 20 bar and $1200^{\circ}$ C", J. Sol. Energy Eng., vol. 123, 2001, pp. 10-17.

[5] Corporate Publication, GE Quartz, Cleveland, OH, USA.

[6] Vogel, W., 1992, Glaschemie, 3rd ed., Springer-Verlag, Berlin, Heidelberg, New York.

[7] Röger, M., Buck, R., Müller-Steinhagen, H., 2005, "Numerical and Experimental Investigation of a Multiple Air Jet Cooling System for Application in a Solar Thermal Receiver", J. Heat Transfer, vol. 127, no. 8, pp. 863-876.

[8] Röger, M., Pfänder, M., Buck, R., 2006: "Multiple Air-Jet Window Cooling for High-Temperature Pressurized Volumetric Receivers: Testing, Evaluation, and Modeling”, J. Sol. Energy Eng., vol. 128, no. 3, pp. 265274.

[9] Uhlig, R.; Röger, M., 2004, "Development of a Window Cooling for High Temperature Solar Receivers", 22nd CAD-FEM Users' Meeting 2004, International Congress on FEM Technology with ANSYS CFX \& ICEM CFD Conference, Nov. 10-12, Dresden, Germany.

[10] Imenes, A.G., Buie, D., Mills, D.R., Schramek, P., Bosi, S.G., 2006, "A New Strategy for Improved Spectral Performance in Solar Power Plants", Solar Energy, vol. 80, pp. 1263-1269.

[11] Green M, Smith W.C., Weiner J.A., 1976, "A thin film electrochromic display based on tungsten bronzes", Thin Solid Films, vol. 38, pp. 89.

[12] Margalith T., Buchinsky O., Cohen D.A., Abare A.C., Hansen M., DenBaars S.P., Coldren L.A., 1999, "Indium tin oxide contacts to gallium nitride optoelectronic devices", Appl. Phys. Lett., vol. 74, no. 26, pp. 3930.

[13] Goodmann L.A., 1974, "Liquid Crystal Displays-ElectroOptic Effects And Addressing Techniques", RCA Review, vol. 35, pp. 613.

[14] Chung C.-H., Ko Y.-W., Kim Y.-H., Sohn H.Y.C., Ko Park S.-H., Lee J.H., 2005, "Radio frequency magnetron sputter-deposited indium tin oxide for use as a cathode in transparent organic light-emitting diode", Thin Solid Films, vol. 491, pp. 294.
[15] Miami T., Ida S., Miyata T., 2002, "High rate deposition of transparent conducting oxide thin films by vacuum arc plasma evaporation", Thin Solid Films, vol. 416, pp. 92.

[16] Sawada M., Higuchi M., 1998, "Electrical properties of ITO films prepared by tin ion implantation in In2O3 film”, Thin Solid Films, vol. 317, pp. 157.

[17] An J.S., Kim S.C., Hahn S.H., Ko S.K., 2004, “Influence of Annealing on the optical and electrical properties of ITO thin films prepared by using a sol-gel spin method", Journ. Korean Phys. Soc., vol. 45, no. 6, pp. 1629.

[18] Luis A., de Caravalho C.N., Lavareda G., Amaral A., Brogueira P., Godinho M.H., 2002, "ITO coated flexible transparent substrates for liquid crystal based devices", Vacuum, vol. 64, pp. 475.

[19] Furman S.h., Tikhonravov A.V., 1992, "Basics of optics of multilayer systems", Editions Frontiers, Gif-sur, Yvette.

[20] Schallenberg U., 2006, "Antireflection design concepts with equivalent layers", Applied Optics, vol. 45, pp. 1507.

[21] Ho J.J., Chen C.Y., Huang C.M., Lee W.J., 2005, "Ionassisted sputtering deposition of antireflection film coating for flexible liquid-crystal display applications", Applied Optics, vol. 44, pp. 6176.

[22] Dombi P., et al., 2005, "Pulse compression with timedomain optimized chirped mirrors", Optics Express, vol. 13, pp. 10888.

[23] Dinca A.G., et al., 1994, "Design of broadband dichroic mirrors using admittance matching", Proc. SPIE, vol. 2253, pp. 120.

[24] Rickers C., et al., 2002, "Design and manufacture of spectrally selective reflecting coatings for the use with laser display projection screens", Applied Optics, vol. 41, pp. 3097.

[25] Rickers C., et al., 2003, "Spectrally selective reflecting thin-film filters for laser display technology", Thin Solid Films, vol 442, pp. 145.

[26] Lange S., et al., 2006, "Pulse magnetron sputtering in a reactive gas mixture of variable composition to manufacture multilayer and gradient optical coatings", Thin Solid Films, vol. 502, pp. 29.

[27] Delano E., 1967, "Fourier Synthesis of multilayer filters", J. Opt. Soc. Am., vol. 57, no. 12.

[28] Dobrowolski J.A., et al., 1978, "Optical thin film synthesis program based on the use of fourier transforms", Appl. Opt., vol. 17, pp. 1966.

[29] Janicki V., et al., 2006, "Deposition and spectral performance of an inhomogeneous broadband wideangular antireflective coating", Applied Optics, vol. 45, pp. 7851.

[30] Hottel, H.C., 1954, "Radiant-Heat Transmission", In: McAdams, W.H. (ed.), "Heat Transmission", 3rd edn., McGraw-Hill Book Company, New York, pp. 55-125.

[31] Hottel, H.C., Sarofim, A.F., 1967, "Radiative Transfer", McGraw-Hill Book Company, New York. 